\title{
Liver biopsy in chronic hepatitis: 1968-78
}

\author{
P. J. SCHEUER
}

From the Department of Histopathology, Royal Free Hospital, London

SUMMARY The classification of chronic hepatitis introduced in 1968 is still current, but has been modified. The concept of bridging hepatic necrosis has been incorporated, and is recognised as an important feature of both acute and chronic aggressive (active) hepatitis (CAH). In the pathogenesis of the latter, piecemeal necrosis is, however, thought to be the more important factor. The histological picture of $\mathrm{CAH}$ varies widely. Several causes of CAH have been identified, including hepatitis $B$ virus. Recognition of surface and core components of the virus in tissue sections has facilitated study of the relationship between host response and pathological lesion in chronic hepatitis. CAH and primary biliary cirrhosis share histological features, and a mixed form has been postulated. Staining for copper sometimes helps to distinguish the two lesions. A third histological category, chronic lobular hepatitis, comprises patients with histological lesions like those of acute hepatitis, but with a chronic or recurrent course.

Ten years ago De Groote et al. (1968) emphasised the need to subdivide chronic hepatitis, according to histological criteria, into categories with differing prognosis. The more benign form, chronic persistent hepatitis (CPH), was characterised by inflammation largely confined to portal tracts, with or without superimposed features of acute hepatitis in the lobules. The essentially benign nature of the lesion has since been confirmed (Becker et al., 1970; Chadwick et al., 1977), although progression to more serious liver disease is recorded (Vido et al., 1969). The other category in the classification of 1968, chronic aggressive hepatitis (CAH), was defined by the presence of piecemeal necrosis, a process of liver-cell destruction at the interface between parenchyma and connective tissue. This category corresponded approximately but not in every respect to the clinical diagnosis of chronic active hepatitis, a term now preferred by many authors for both histological and clinical description. Cirrhosis develops in a variable and often high proportion of patients with CAH (Dietrichson and Christoffersen, 1977).

This classification of chronic hepatitis, though not universally accepted, is still widely used and 10 years after its publication liver biopsy continues to play a major part in the diagnosis and management of patients with chronic hepatitis. The purpose of the present paper is to review the changes which have taken place since 1968 in the nomenclature and classification of chronic hepatitis, in the techniques which can be applied to biopsy tissue, and in the understanding of biopsy findings.

\section{Aetiology of CAH}

In 1968 the aetiology of CAH was largely a matter for speculation, although a relationship between some instances of CAH and viral hepatitis was assumed. The hepatitis $B$ surface antigen (HBsAg) had been discovered a few years previously (Blumberg et al., 1965), and proved to be present in a variable proportion of patients with CAH (Dudley et al., 1972). Techniques became avilable for demonstrating HBsAg by empirical and specific immunological methods in liver tissue: by means of these and electron microscopy, surface components of the virus could be identified in the cytoplasm of some liver cells (Gerber et al., 1974; Shikata et al., 1974; Ray and Desmet, 1975; Burns, 1975). The virus core antigen (HBcAg) can be identified by electron microscopy and by immunological methods, mainly in liver-cell nuclei. The relationship between $\mathrm{HBcAg}$ and $\mathrm{HBsAg}$ in the various forms of chronic hepatitis has been studied by Gudat et al. (1975) and Ray et al. (1976). Gudat and coworkers postulate that four main patterns of distribution of the virus components reflect different immunological responses of the patients to the virus infection. The normal response is elimination of the virus, and a short self-limiting attack of acute hepatitis. In a minority of patients virus continues to multiply 
in the liver. Either surface or core antigens may predominate, the latter typically in the patient on immunosuppressive drugs. Presence of both components in approximately equal amounts (the equivalence pattern) is characteristic of the more severe forms of chronic liver disease. Since the immunological patterns do not correspond exactly to the histological categories of chronic hepatitis, demonstration of virus components in liver biopsies may provide useful prognostic information, not obtainable by conventional light microscopy alone.

It has not proved possible so far to distinguish other aetiological types of chronic active hepatitis histologically with any degree of certainty. In addition to type $B$ hepatitis, other causes to be considered include an immunological reaction, possibly directed against liver-cell-membrane components ('lupoid hepatitis'), drugs such as alphamethyldopda, isoniazid and oxyphenisatin (Goldstein et al., 1973), and Wilson's disease (Sternlieb and Scheinberg, 1972). More recently, it has been pointed out that patients with chronic hepatitis may give a history of excess drinking, and alcohol is now considered as one of the many agents that are capable of triggering the immunological reaction visualised in liver biopsy specimens as CAH (Goldberg et al., 1977).

\section{Relationship of CAH and bridging hepatic necrosis}

Soon after 1968, Boyer and Klatskin (1970) pointed out that in a group of patients with viral hepatitis the presence of necrosis linking the various vascular structures of the hepatic lobule carried a poor prognosis. Patients with bridging hepatic necrosis were much more likely to die of liver failure within months of the onset of the hepatitis than were those with the classical lesion of viral hepatitis, characterised by spotty necrosis. Patients with bridging also developed chronic liver disease more often. The bridges linked adjacent centrilobular veins, adjacent portal tracts, or both. Peters (1975) has argued that the poor prognosis of patients with bridging necrosis may reflect their greater age and hence the impaired regenerative capacity of their livers, but, whatever the underlying mechanism of the worse prognosis, there is no doubt that confluent bridging necrosis may be found in the livers of patients with $\mathrm{CAH}$, and that it modifies the histological picture.

The term bridging necrosis has been used for different kinds of bridges, and it is necessary to clarify the part played by each kind. Bianchi et al. (1977) consider that bridges linking centrilobular veins to each other or to portal tracts are qualitatively different from those joining portal tracts. They postulate that the first two are examples of confluent necrosis, whereas the last represents a form of piecemeal necrosis. Bridges linking centrilobular veins to each other probably play little part in the pathogenesis of CAH. In the remainder of this review, the term bridging hepatic necrosis (BHN) will be restricted to bridges of confluent necrosis linking centrilobular and portal structures. Their location is difficult to explain on the basis of the lobular concept of hepatic structure, and they are thought to represent confluent necrosis at the periphery of Rappaport's simple acinus; bridging between adjacent efferent (centrilobular) veins is postulated to occur as a result of similar necrosis at the periphery of complex acini (Rappaport, 1976).

Bianchi et al. (1977) favour the view that $\mathrm{BHN}$ is not by itself an important prognostic or pathogenetic feature in the development of chronic liver disease, and that uncomplicated BHN normally undergoes healing with partial or complete resolution. This is supported by the observation of Karvountzis et al. (1974) that the livers of some patients with massive hepatic necrosis who survive the acute attack return to normal. In drug-induced hepatic necrosis, which may include $\mathrm{BHN}$, healing is the rule (Portmann et al., 1975). Piecemeal necrosis, including the form seen as portal-to-portal bridging, is thought to be the more important pathogenetic factor and can be recognised early in the course of acute viral hepatitis. The ensuing lesion of chronic active hepatitis varies greatly in severity and in the extent to which lobular structure is altered. It is assumed that the presence of BHN leads to more rapid progression to cirrhosis, by altering the hepatic architecture and forming intrahepatic portal-systemic shunts, and possibly by facilitating immunological reactions deep within the lobules.

\section{CAH and primary biliary cirrhosis}

Piecemeal necrosis, mononuclear-cell infiltration, and fibrosis are common to CAH and primary biliary cirrhosis (PBC), and both may end in cirrhosis. There is therefore overlap in the histological features of the two diseases, occasionally leading to difficulty in distinguishing them on liver biopsy. This difficulty is compounded by the fact that not all patients with PBC have antimitochondrial antibodies in the serum, and in a minority the typical clinical features of PBC, such as pruritus, are absent (Sherlock and Scheuer, 1973). Usually, attention to histological details enables the correct diagnosis to be made even in the absence of clear-cut clinical, biochemical and immunological data. Helpful features suggesting PBC include bile duct damage, 
granuloma formation, partial preservation of lobular or acinar structure, irregularly distributed fibrosis, paucity of bile ducts, proliferation of ductules, and focal accumulations of lymphocytes. These mark the sites of destroyed bile ducts. Staining for copper may also be helpful. Copper is largely excreted in the bile, and in diseases with chronic cholestasis such as PBC large amounts of copper accumulate in the liver (Hunt et al., 1963; Fleming et al., 1974). A copper-associated protein can be demonstrated in liver cells in such patients by means of staining with orcein (Salaspuro and Sipponen, 1976). Jain et al. (1977) have found good correlation between liver copper levels as estimated by neutron activation, and staining for copper or copper-associated protein. Intense staining appears to favour a diagnosis of PBC over CAH.

The existence of a third category, with features of both PBC and CAH, has recently been supported by a study of antibodies against different mitochondrial fractions (Klöppel et al., 1977). Liver biopsies of patients with antimitochondrial antibodies unlike those of classical PBC commonly showed very active hepatocellular damage and intense ductular proliferation.

\section{A third category of chronic hepatitis}

An international group sponsored by the John E. Fogarty International Center and the International Association for the Study of the Liver (US Government Printing Office, 1976) has defined chronic hepatitis as inflammation of the liver continuing without improvement for at least six months'. There are patients, who according to these criteria have chronic hepatitis, whose liver biopsy appearances are not those of CPH or CAH. Liver-cell necrosis and degeneration, Kupffer-cell proliferation, and inflammatory-cell infiltration are seen in the lobules as in acute viral hepatitis, but portal and periportal inflammation are inconspicuous. Popper and Schaffner (1971) designated this lesion chronic lobular hepatitis (CLH), a term which corresponds to the other categories of chronic hepatitis. Prolonged or protracted hepatitis is used in a similar way. Ishak (1973) and Peters (1975) refer to persistent viral hepatitis and unresolved viral hepatitis, using these terms to include both portal and intralobular changes. Their categories are thus an amalgam of CPH and CLH. CLH without substantial portal inflammation appears to be relatively rare, and is sometimes marked by a distinctive clinical picture of repeated episodes resembling acute hepatitis but responding to corticosteroids (Wilkinson et al., 1977). Theoretically, CLH is of considerable interest, as it presumably represents an immunological response to hepatitis virus infection that is different from the one responsible for CAH. The long-term outlook for patients with CLH appears to be good, but more studies are needed to confirm or refute this impression.

\section{Liver biopsy and clinical course of chronic hepatitis}

Finally, it is necessary to reassess the current histological classification of chronic hepatitis in the light of 10 years' use. The need to recognise bridging hepatic necrosis and to incorporate it into the concept of CAH has already been discussed. The presence of bridging necrosis between portal tracts and efferent veins, as well as the extent of piecemeal necrosis and the associated mononuclearcell infiltration, determine the character and severity of the disease. CAH may thus vary from a minimal lesion, distinguishable with difficulty from $\mathrm{CPH}$, to one with complete disruption of hepatic architecture, widespread necrosis and inflammation, formation of liver-cell rosettes and nodular regeneration. Between these two extremes are examples of CAH of moderate severity, without cirrhosis, and therefore at least potentially reversible. All three varieties fulfil the criteria of $\mathrm{CAH}$ as proposed by De Groote et al. (1968) and modified by Bianchi et al. (1977). Their effect on the patient, their prognosis, and the need for active treatment, however, differ. It is therefore suggested that there are significant subcategories within the histological spectrum of $\mathrm{CAH}$, ranging from a minimal lesion more akin to CPH to an active cirrhosis. This heterogeneity of CAH should be kept in mind when therapeutic and other studies of $\mathrm{CAH}$ are assessed.

\section{References}

Becker, M. D., Scheuer, P. J., Baptista, A., and Sherlock, S. (1970). Prognosis of chronic persistent hepatitis. Lancet, 1, 53-57.

Bianchi, L., De Groote, J., Desmet, V. J., Gedigk, P., Korb, G., Popper, H., Poulsen, H., Scheuer, P. J., Schmid, M., Thaler, H., and Wepler, W. (1977). Acute and chronic hepatitis revisited. Lancet, 2, 914-919.

Blumberg, B. S., Alter, H. J., and Visnich, S. (1965). A 'new' antigen in leukemia sera. Journal of the American Medical Association, 191, 541-546.

Boyer, J. L., and Klatskin, G. (1970). Pattern of necrosis in acute viral hepatitis. Prognostic value of bridging (subacute hepatic necrosis). New England Journal of Medicine, 283, 1063-1071.

Burns, J. (1975). Immunoperoxidase localisation of hepatitis B antigen (HB) in formalin-paraffin processed liver tissue. Histochemistry, 44, 133-135.

Chadwick, R. G., Galizzi, J., Heathcote, E. J., Cohen, B., Scheuer, P. J., and Sherlock, S. (1977). Natural history of chronic persistent hepatitis (Abstract). Gut, 18, A951.

De Groote, J., Desmet, V. J., Gedigk, P., Korb, G., Popper, H., Poulsen, H., Scheuer, P. J., Schmid, M., Thaler, H., 
Uehlinger, E., and Wepler, W. (1968). A classification of chronic hepatitis. Lancet, 2, 626-628.

Dietrichson, O., and Christoffersen, P. (1977). The prognosis of chronic aggressive hepatitis. A clinical and morphological follow-up study. Scandinavian Journal of Gastroenterology, 12, 289-295.

Dudley, F. J., Scheuer, P. J., and Sherlock, S. (1972). Natural history of hepatitis-associated antigen-positive chronic liver disease. Lancet, 2, 1388-1393.

Fleming, C. R., Dickson, E. R., Baggenstoss, A. H., and McCall, J. T. (1974). Copper and primary biliary cirrhosis. Gastroenterology, 67, 1182-1187.

Gerber, M. A., Hadziyannis, S., Vissoulis, C., Schaffner, F., Paronetto, F., and Popper, H. (1974). Electron microscopy and immunoelectronmicroscopy of cytoplasmic hepatitis B antigen in hepatocytes. American Journal of Pathology, 75, 489-502.

Goldberg, S. J., Mendenhall, C. L., Connell, A. M., and Chedid, A. (1977). 'Nonalcoholic' chronic hepatitis in the alcoholic. Gastroenterology, 72, 598-604.

Goldstein, G. B., Lam, K. C., and Mistilis, S. P. (1973). Drug-induced active chronic hepatitis. American Journal of Digestive Diseases, 18, 177-184.

Gudat, F., Bianchi, L., Sonnabend, W., Thiel, G., Aenishaenslin, W., and Stalder, G. A. (1975). Pattern of core and surface expression in liver tissue reflects state of specific immune response in hepatitis B. Laboratory Investigation, 32, 1-9.

Hunt, A. H., Parr, R. M., Taylor, D. M., and Trott, N. G. (1963). Relation between cirrhosis and trace metal content of liver. British Medical Journal, 2, 1498-1501.

Ishak, K. G. (1973). Viral hepatitis: the morphologic spectrum. In The Liver, pp. 218-268. Edited by E. A. Gall and F. K. Mostofi. Williams and Wilkins: Baltimore.

Jain, S., Scheuer, P. J., Archer, B., Newman, S., and Sherlock, S. (1977). Histochemical demonstration of liver copper and copper-carrying protein in chronic liver disease (Abstract). Gut, 18, A953-A954.

Karvountzis, G. G., Redeker, A. G., and Peters, R. L. (1974). Long term follow-up studies of patients surviving fulminant viral hepatitis. Gastroenterolggy, 67, 870-877.

Klöppel, G., Seifert, G., Lindner, H., Dammermann, R., Sack, H. J., and Berg, P. A. (1977). Histopathological features in mixed types of chronic aggressive hepatitis and primary biliary cirrhosis. Correlations of liver histology with mitochondrial antibodies of different specificity. Virchows Archiv; A: Pathological Anatomy and Histology, 373, 143-160.
Peters, R. L. (1975). Viral hepatitis: a pathologic spectrum. American Journal of the Medical Sciences, 270, 17-31.

Popper, H., and Schaffner, F. (1971). The vocabulary of chronic hepatitis. New England Journal of Medicine, 284, 1154-1156.

Portmann, B., Talbot, I. C., Day, D. W., Davidson, A. R., Murray-Lyon, I. M., and Williams, R. (1975). Histopathological changes in the liver following a paracetamol overdose: correlation with clinical and biochemical parameters. Journal of Pathology, 117, 169-181.

Rappaport, A. M. (1976). The microcirculatory acinar concept of normal and pathological hepatic structure. Beiträge zur Pathologie, 157, 215-243.

Ray, M. B., and Desmet, V. J. (1975). Immunofluorescent detection of hepatitis $B$ antigen in paraffin-embedded liver tissue. Journal of Immunological Methods, 6, 283-289.

Ray, M. B., Desmet, V. J., Bradburne, A. F., Desmyter, J., Fevery, J., and De Groote, J. (1976). Differential distribution of hepatitis B surface antigen and hepatitis B core antigen in the liver of hepatitis B patients. Gastroenterology, 71, 462-469.

Salaspuro, M., and Sipponen, P. (1976). Demonstration of an intracellular copper-binding protein by orcein staining in long-standing cholestatic liver diseases. Gut, 17, 787-790.

Sherlock, S., and Scheuer, P. J. (1973). The presentation and diagnosis of 100 patients with primary biliary cirrhosis. New England Journal of Medicine, 289, 674-678.

Shikata, T., Uzawa, T., Yoshiwara, N., Akatsuka, T., and Yamazaki, S. (1974). Staining methods of Australia antigen in paraffin section. Detection of cytoplasmic inclusion bodies. Japanese Journal of Experimental Medicine, 44, 25-36.

Sternlieb, I., and Scheinberg, I. H. (1972). Chronic hepatitis as a first manifestation of Wilson's disease. Annals of Internal Medicine, 76, 59-64.

U.S. Government Printing Office (1976). Diseases of the Liver and Biliary Tract. Standardization of Nomenclature, Diagnostic Criteria, and Diagnostic Methodology, pp. 9-11. (Fogarty International Center Proceedings No. 22.) DHEW Publication No. (NIH) 76-725: Washington.

Vido, I., Selmair, E., Wildhirt, E., and Ortmans, H. (1969). Zur Prognose der chronischen Hepatitis. 1. Formen und Entwicklungsstadien. Deutsche Medizinische Wochenschrift, 94, 2215-2220.

Wilkinson, S. P., Portmann, B., Cochrane, A. M. G., and Williams, R. (1977). Chronic lobular hepatitis: a distinct entity? (Abstract). Gut, 18, A951-A952. 